\title{
Establishment and implementation of a psychiatry enrichment programme for medical students
}

Zaza Lyons Assistant Professor, School of Psychiatry and Clinical Neurosciences, University of Western Australia, Crawley, WA, Australia

\begin{abstract}
Objective: There has been a growing interest in psychiatry enrichment programmes such as summer schools and institutes for medical students in the last 10 years. Evaluation of enrichment programmes shows that they can be an effective method of increasing students' interest in psychiatry as a career. However, despite initial enthusiasm and motivation within an academic department, establishing a programme can be a daunting task. The aim of this paper is to provide a background of how to establish and implement a psychiatry summer school or institute. The steps that can be taken to establish and implement a psychiatry enrichment programme such as a summer school or institute are described and discussed. This includes how to structure a programme, content to include, costs and budget, programme promotion, selection of students and programme evaluation.

Conclusion: Establishing an enrichment programme can provide academic departments of psychiatry with the opportunity to demonstrate excellence and innovation in teaching and positively promote psychiatry to students and other non-medical academics involved in medical education. For students interested in psychiatry, enrichment programmes have the potential to extend interest and knowledge beyond the curriculum and encourage serious consideration of psychiatry as a career.
\end{abstract}

Keywords: medical student, psychiatry enrichment programme, summer school, career

I nterest in psychiatry enrichment programmes has grown substantially over the last 10 years. An enrichment programme is usually established by an academic department to increase medical students' interest in psychiatry, improve attitudes towards psychiatry, and promote psychiatry as an attractive career choice. ${ }^{1}$ Enrichment programmes provide academic departments with a platform for students to explore psychiatry in greater depth and breadth than is possible in the medical curriculum, and enable psychiatry as a medical specialisation and potential career to be showcased and promoted. $^{2}$

Enrichment programmes may be formally structured as a series of elective modules and integrated throughout the medical course over a period of years to supplement the existing curriculum, e.g. the combined accelerated programme in psychiatry (University of Maryland) and the study focus on psychiatry programme in Zurich. ${ }^{3,4}$ More commonly however, a programme is established as a standalone summer school or institute and is run annually for between 1 and 5 days, e.g. the Toronto Institute of Psychiatry for Medical Students and the Claassen Institute of Psychiatry for Medical Students in Western Australia (the Claassen Institute). 5,6
There is growing evidence of the effectiveness of enrichment programmes in increasing interest in psychiatry as a career. For example, long-term evaluation of the Toronto Institute showed that of students who attended the programme between 1994 and 2005, 43\% matched in to postgraduate psychiatry training. ${ }^{7}$ Similarly, evaluation of the Claassen Institute found a significant increase in career interest among students who attended between 2008 and 2014. ${ }^{8}$ Both of these programmes have been highly rated by students, and these encouraging results may well lead to more academic departments considering implementing similar programmes. However, for the uninitiated this may be a daunting task. Drawing on the author's experience of co-ordinating the Claassen Institute, the aim of this paper is to provide a background of how to establish and implement a psychiatry summer school or institute.

\section{Corresponding author:}

Zaza Lyons, School of Psychiatry and Clinical Neurosciences, University of Western Australia, 35 Stirling Highway, Crawley, WA 6009, Australia.

Email: zaza.lyons@uwa.edu.au 


\section{Where to start}

A good starting point is to team up with like-minded colleagues to gain a commitment to proceed with establishing a programme. Initial questions to consider are:

- Do we have the support and enthusiasm of colleagues, heads of departments to do this?

- Do we have the time to devote to establishing, setting up and implementing a programme?

- What do we want the programme to achieve?

- Do we have the financial resources required to run a programme?

- Can we deal with the logistics; for example, are there rooms and equipment available to run seminars and other sessions?

If the answer to these questions is 'yes' then more detailed planning can begin.

\section{Programme length}

The basic structure of the programme needs to be decided. Summer schools and institutes are often run as 5-day programmes, but can be less if resources are limited. Alternatively, a programme can be run over a weekend, or series of weekends. The length of the programme is often determined by the budget and time available. The longer the programme the more content and activities can be covered; however, costs may be higher. An important consideration is when to run the programme and this depends on the academic calendar, timing of exams and other curricula matters.

\section{Programme content and structure}

An introductory welcome by the department head and allocation of time for icebreakers will get the programme off to a good start. A combination of seminars and elective visits each day is a good basic structure to follow. Two or three morning seminars presented by local experts, and afternoon elective visits on 2-3 days provides a balance of different activities. Seminars that cover topics not taught in the curriculum, in particular areas of psychiatric research and/or subspecialisation that students may not be familiar with, will raise career interest and improve knowledge of different aspects of psychiatry. Seminars of one hour including question time is optimal. Detailed information about the local postgraduate training programme that provides students with sufficient information to make informed career decisions and ask specific questions is an essential component of any programme.

As well as talking about their area of expertise, presenters can also describe a working day in their area of specialization, which gives students different perspectives of psychiatry and a realistic view of what working as a psychiatrist entails. Sharing their journey from medical student to consultant psychiatrist, and what attracted them to the speciality, are appreciated by students.

Students particularly like less didactic activities that are interactive and engaging. Debates, case-based discussions, patient panels, an art or media component, and 'speed dating' are all highly rated and are easily incorporated into the programme. Debate topics can focus on contemporary and controversial issues and post-debate discussion facilitated by a consultant psychiatrist specialising in the area relevant to the debate topic.

Attending clinical elective sessions is an important component of a programme; however, organising them can be time consuming and arrangements need to be made well in advance. Arranging the visits with local mental health service providers that students have not had contact with during the clerkship will broaden their exposure to, and knowledge of, the allied mental health system. These include community providers, specialised hospital departments, and the not-for-profit and nongovernmental sectors.

Mentoring can be incorporated into a summer school programme with the additional benefit that students will be matched with a senior academic or clinician who shares the same career aspirations and goals, and has faced similar career decision-making processes. ${ }^{3}$ Enrichment programmes are also ideal environments within which to address stigma and provide students with knowledge and skills to overcome its negative effect.

Opportunities such as morning tea and lunch to meet and chat informally with consultants and registrars are also well received and easily integrated into the programme. The presentation of certificates of participation provide students with a sense of achievement and ends the programme on a positive note. Photographs also provide mementos for students and presenters alike.

\section{Organising the programme}

Establishing an organising committee will assist with the various tasks that need to be undertaken to implement the programme. Administrative support is also essential to assist with logistical matters such as room hire and catering. Naming the programme, developing a logo and other artwork that can be used in promotional materials creates a sense of identity. Some programmes are promoted to students from several universities and most have a formal application process whereby students are required to submit a written application detailing why they are interested in attending. Selection of students is a further task for an organising committee.

\section{Selection of students to attend a programme}

Programme places are usually limited. Twenty is an optimal number that encourages a good group dynamic and 
Table 1. Selection of students to attend a summer school programme

\begin{tabular}{|c|c|c|}
\hline & Advantages & Disadvantages \\
\hline Preclinical years only & $\begin{array}{l}\text { - Increases career interest in early } \\
\text { stages of medical school. } \\
\text { - Opportunities to establish ongoing } \\
\text { mentoring relationships to maintain } \\
\text { long-term interest. } \\
\text { - Improves knowledge and skills which } \\
\text { will give a head start to the clinical } \\
\text { clerkship. }\end{array}$ & $\begin{array}{l}\text { - Less prior knowledge of core clinical } \\
\text { psychiatric knowledge, which may } \\
\text { limit interaction and engagement with } \\
\text { programme content. } \\
\text { - Initial interest may deteriorate as student } \\
\text { progress through medical school. } \\
\text { - Programme may need to be modified to } \\
\text { account for lower knowledge level. } \\
\text { - Electives visits may not be appropriate. } \\
\text { - Excludes students in clinical years who } \\
\text { have become interested in psychiatry post- } \\
\text { clerkship. }\end{array}$ \\
\hline $\begin{array}{l}\text { Clinical years and 'decided' } \\
\text { on psychiatry as a career }\end{array}$ & $\begin{array}{l}\text { - Introduces students to areas of } \\
\text { subspecialisation that they have little } \\
\text { knowledge of, which can help with } \\
\text { career planning. } \\
\text { - Programme content can be targeted at } \\
\text { a higher, more challenging level. } \\
\text { - Opportunities to establish ongoing } \\
\text { mentoring relationships to maintain } \\
\text { long-term interest. }\end{array}$ & $\begin{array}{l}\text { - Pool of potential applicants may be small. } \\
\text { - Excludes 'thinking about' and 'undecided' } \\
\text { students. } \\
\text { - Excludes preclinical students who may be } \\
\text { interested. } \\
\text { - Preaching to the converted. } \\
\text { - If recruitment rates are used as a long-term } \\
\text { outcome measure, may positively skew } \\
\text { success of the programme if they do pursue. }\end{array}$ \\
\hline $\begin{array}{l}\text { Clinical years and 'thinking } \\
\text { about' psychiatry as a career }\end{array}$ & $\begin{array}{l}\text { - Introduces students to areas of } \\
\text { subspecialisation that they have little } \\
\text { knowledge of, which can help with } \\
\text { career planning. } \\
\text { - Provides opportunity to 'win them over' } \\
\text { and 'get them over the line' regarding } \\
\text { psychiatry as a career. } \\
\text { - Programme content can be targeted at } \\
\text { a higher, more challenging level. } \\
\text { - Opportunities to establish ongoing } \\
\text { mentoring relationships to maintain } \\
\text { long-term interest. }\end{array}$ & $\begin{array}{l}\text { - May put them off psychiatry as career. } \\
\text { - Excludes 'decided' students denying } \\
\text { them the opportunity to learn more about } \\
\text { psychiatry. } \\
\text { - May alienate 'decided' students. } \\
\text { - Excludes preclinical students who may be } \\
\text { interested. } \\
\text { - If recruitment rates are used as a long-term } \\
\text { outcome measure, may negatively skew } \\
\text { evaluation of the programme if they decide } \\
\text { not to pursue. }\end{array}$ \\
\hline
\end{tabular}

enables students, presenters and organisers to get to know one another. This means that careful consideration needs to be given to deciding which students should be targeted to participate in the programme. As most programmes aim to attract students to choose psychiatry as a career, ${ }^{1}$ there are a number of different selection options that can be considered. Table 1 lists some advantages and disadvantages of choosing preclinical versus clinical students, and those 'thinking about' a career in psychiatry compared with those who have 'definitely' chosen psychiatry as a career. While there is no clear consensus on which students to select, targeting clinical students who have undertaken a clerkship and are closer to making career decisions may make the experience more meaningful and provide programme organisers with the opportunity to build on and extend their existing interest and knowledge.

\section{Programme costs}

The programme can be adapted to the available budget and resources. Catering is one of the major overheads, and while this can be done relatively cheaply, programme length and student numbers will impact on the daily catering costs. Providing morning tea and lunch, and breakfast if there are early morning starts, are standard components of most programmes. If the budget permits, assisting non-local students with subsidising travel and accommodation costs, and inviting special guests are optional extras. 
Raising funding externally from the local health department, private sector or other sources that have an interest in supporting mental health causes can be considered. Jointly collaborating and partnering with other universities and/or health organisations to share costs may be more feasible in some jurisdictions. Running a programme bi-annually is an option if funding is limited. There also needs to be a commitment for long-term funding of the programme to ensure that it is sustainable over time.

\section{Programme evaluation}

Evaluation is important to ensure that the programme meets its aims and goals and is usually undertaken by administering questionnaires at the beginning and end of the programme. Demographic information and an opportunity for students to provide open-ended feedback about the programme should be included. As well as questionnaires, focus groups can be convened, which will provide a useful qualitative perspective to data collection. Evaluation can also provide evidence of the programme's success, which may be important in securing long-term funding. Formal evaluation of the programme will require ethics approval and this needs to be organised well in advance of the start date.

As final career decisions may not be made for some years after a student has participated in a programme, ${ }^{9}$ longitudinal evaluation to determine if the 'here and now' interest endures through the remainder of medical school and internship should be embedded within the evaluation. This may be difficult due to problems in following students over longer periods of time, especially after graduation from medical school when their university email address and other contact details change. Recording a non-university email address so that students can be contacted to participate in further surveys in the post-programme years can overcome this.

\section{Conclusion}

For students interested in psychiatry, enrichment programmes such as summer schools and institutes have the potential to extend interest and knowledge beyond the curriculum and encourage serious consideration of psychiatry as a career. From a student perspective there are a number of advantages in participating in a programme. Attending a summer school or institute will assist in making a career decision and even if psychiatry is not the choice, participating will have played an important part in the process. Students enjoy mixing with like-minded peers who all share a common interest in psychiatry. Some ex-students may volunteer to organise future programmes and this will ensure that a student perspective is maintained over time.

Enrichment programmes also offer a good opportunity for academic departments to demonstrate excellence and innovation in teaching and positively promote psychiatry to both students and non-psychiatry academics involved in medical education. Finally, as the trend towards the establishment of enrichment programmes grows it is important that academics and researchers share their experiences and expand the evidence base.

\section{Disclosure}

The author reports no conflict of interest. The author alone is responsible for the content and writing of the paper.

\section{Funding}

The author received no financial support for the research, authorship, and/or publication of this article.

\section{References}

1. Lyons Z. Psychiatry enrichment initiatives: a review of current programs, summer schools, and institutes. Acad Psychiatry 2016; D0I: 10.1007/s40596-016-0512-4

2. Lyons $Z$, Hans $D$ and Janca A. Future proofing the psychiatry workforce in Australia: evaluation of an innovative enrichment programme for medical students. Australas PSychiatry 2015; 23: 584-588.

3. Manassis K, Katz M, Lofchy J, et al. Choosing a career in psychiatry: influential factors within a medical school program. Acad Psychiatry 2006; 30: 325-329.

4. Gerke W, Rufer M and Schnyder U. Attracting young academics into the field of psychiatry and psychotherapy in Switzerland - the Zurich 'study focus on psychiatry' and training concept for medical psychotherapy. Int Rev Psychiatry 2013; 25: 445-459.

5. Weintraub W, Plaut M and Weintraub E. Recruitment into psychiatry: increasing the pool of applicants. Can J Psychiatry 1999; 44: 473-477.

6. Lofchy J, Brunet A and Silver I. The Psychiatry Institute for Medical Students: a novel recruitment strategy. Acad Psychiatry 1999; 23: 151-156.

7. Lyons Z, Power B, Bilyk N, et al. The University of Western Australia Institute of Psychiatry for Medical Students: an Australian first. Australas Psychiatry 2009; 17: 306-310.

8. Andermann L, De Souza C and Lofchy J. The Psychiatry Institute for Medical Students: a decade of success. Acad Psychiatry 2010; 34: 150-153.

9. Harris $M$, Gavel $P$ and Young J. Factors influencing the choice of specialty of Australian medical graduates. MJA 2005; 183: 295-300. 